\title{
The Influence of "Wandering Earth" on Chinese Cultural Soft Power*
}

\author{
Ling Ye \\ School of Foreign Languages \\ Hubei Engineering University \\ Xiaogan, China 432000
}

\begin{abstract}
Wandering Earth" became a phenomenal film in 2019, and won a double harvest at the box office and word of mouth. Some people commented on it as "China's first science fiction blockbuster", and others commented that its emergence opened the "first year of Chinese science fiction". The success of "Wandering Earth" shows that the production level of Chinese science fiction films has been greatly improved. Also, its success benefits from China's economic development and the advancement of science and technology. "Wandering Earth" has had a major impact on the improvement of Chinese cultural soft power. It not only promotes the development of Chinese science fiction movies, promotes the core values of Chinese tradition, and reshapes China's national image, and but also has a unique position in the history of Chinese science fiction films.
\end{abstract}

Keywords-"Wandering Earth"; science fiction film; cultural soft power

\section{INTRODUCTION}

On February 5, 2019 (first day of the lunar year), "Wandering Earth" was officially released. During the Spring Festival, films with high levels of topics such as "crazy aliens", "the new king of comedies" and "Pegasus" are also released at the same time. As a science fiction film, "Wandering Earth" is like a dark horse, and it has won a double harvest at the box office and word of mouth. As of March 11, 2019, the cumulative box office of the film has exceeded 4.6 billion Yuan. Some experts predict that its box office is expected to exceed 5 billion Yuan, second only to the No. 1 "Wolf Warriors II". At the same time, the audience in China and foreign countries also rated the film quite high. After watching "Wandering Earth", the famous playwright and critic Zhao Yuhua commented: "No matter whether it is written or produced, it has achieved a subversive and innovative expression." The famous American director James Cameron said: "The point I like about 'Wandering Earth' is that it makes a very radical concept into a film, making it acceptable to people." All of this has sparked heated discussions among the public. This shows that "Wandering Earth" is undoubtedly a phenomenal film in the history of Chinese cinema. This film is not only a sci-fi film with "hard technology", but also highlights

*The Humanities and Social Sciences Foundation Project of Hubei Education Department of China — "Research on the Development of College English Teachers Based on Blended Learning Model" (Project No. 19Q171).
China's "soft culture", which has a tremendous impact on the improvement of the soft power of Chinese film culture.

\section{CUltural SOFT POWER AND FILM}

Regarding the concept of "cultural soft power", there is currently no unified definition in the academic world. The understanding of it goes back to the concept of "soft power" proposed by Professor Joseph S. Nye of Harvard University in 1990. He believes that a country's overall national strength consists of "hard power" and "soft power". "Hard power" is manifested in a country's economy, science and technology, military strength, etc., and "soft power" includes the attraction of culture and values, social systems, development models, lifestyles and ideologies. From the definition given by Joseph S. Nye, it can find that "cultural soft power" is derived from "soft power", and there is a connotation and extension relationship between them.

In a country's development, the economy can be an explicit manifestation, and culture is its inner soul. Therefore, if a country wants to make great progress, it must work along both lines. Since the 18th National Congress of the Communist Party of China, General Secretary Xi Jinping has attached great importance to the development of national cultural soft power. He emphasized: "The cultural soft power embodies the cohesiveness, vitality, the resulting attraction and influence of a country based on culture." In the 19th National Congress of the Communist Party of China, X Jinping proposed "to promote the international communication capacity building of Chinese culture, to tell the Chinese story, to show the true, three-dimensional and comprehensive China, and to improve the national cultural soft power". This also reflects the importance the state attaches to the construction of "cultural soft power".

"Film culture" is an important part of "cultural soft power." The film is not restricted by geography and has a wide spread. At the same time, the film has threedimensional presentation, rich themes, strong visual impact and other characteristics, making it occupy a pivotal position in many cultural styles. In the process of watching movies, the audience's values will be subtly influenced, which has played an important role in promoting a country's culture. Therefore, as an important carrier of "cultural soft power", the film has also received attention from all parties. In 2010 the General Office of the State Council issued the "Guiding Opinions of the General Office of the State Council on 
Promoting the Prosperity and Development of the Film Industry": "We will vigorously promote the leap-forward development of China's film industry and realize the historic transformation from a big country of film to a film power."

The emergence of "Wandering Earth" has milestone significance, and it is known as "the ground breaking work of China's hard nuclear science fiction". Hu Zhifeng, dean of the School of Art and Media at Beijing Normal University, believes that "Wandering Earth" is a new benchmark for Chinese films in the new era to embody the spirit of a big country, to demonstrate the power of a big country, and to showcase the style of a big country. The "Wandering Earth" has had a tremendous impact on the soft power of Chinese film culture.

\section{III. "WANDERING EARTH" PROMOTES THE SOFt POWER OF CHINESE CULTURE}

\section{A. Promoting the Development of Chinese Science Fiction Films}

There is a certain gap between the development of Chinese science fiction films and the world famous Hollywood science fiction films. Early Chinese science fiction films were restricted by social environment, technical means, innovative thinking, technological development, and creative experience and funding. They were in a weak position among many types of films. Some scholars even believe that Chinese science fiction films in the past cannot be counted as a "science fiction film" in the true sense.

It is understood that the earliest domestic science fiction film was born in 1938, namely, "Visiting Shanghai after Sixty Years". The film tells the story of a "passing through": two company employees have the idea of transforming the family and transforming the world. As the earth flew, the two immediately traveled to Shanghai 60 years later. There are fantasies about the advanced technologies of the future world, such as flying cars and automatic home appliances. Although this kind of idea was relatively advanced in the Chinese society at that time, it was not supported by scientific theory. Thereby, it was controversial to call it a science fiction film. Twenty years later, in 1958, the second science fiction "The Ming Tombs Reservoir" was launched with the theme of "moon travel". In 1963, a children's science fiction film "Little Sun" was released. In the 1980s, domestic science fiction films ushered in a small period of glory. At this stage, the number of films has increased significantly, such as "Dead Coral Island" (1980), "Live Shadow" (1981), "Indulge in the wildest fantasy" (1986), "Dislocation" (1987), "Wonder boy" (1988) ), "The Head in the House" (1989), "The Lost Atmosphere" (1990), "The Invisible Doctor" (1992), etc. After entering the 21st century, there have also been some films with science fiction factors, such as "Space Rescue" (2001), "Changjiang No. 7" (2008), "Metallic Attraction Kungfu Cyborg" (2009), "Future X-Cops" (2010), etc. The above-listed films all contain "science fiction elements", following the definition of "science fiction films" in the "Movie Art Dictionary", that is, "story films with scientific fantasy as content". The basic feature is to make a fantasy description of the future world or the distant past from the scientific principles and scientific achievements known today. They are not counted as "science fiction films" in the strict sense.

Until the release of "Wandering Earth" on February 5, 2019, industry experts thought it opened the "first year of Chinese science fiction films". "The Wandering Earth" was adapted from Liu Cixin's novel of the same name. As a hard science fiction writer, he won the "Galaxy Award", the highest award for Chinese science fiction. In 2016, he won the Hugo Award from the World Science Fiction Association for his science fiction novel "The Three-Body Problem", which also raised the level of Chinese science fiction to the height of the world. In the history of science fiction and art development in China and the world, Liu Cixin's status can be seen.

The background of "Wandering Earth" is set in 2075, telling that the sun is about to be destroyed, and human beings are facing great threats. In order to survive, human beings will start the "Wandering Earth" plan, trying to escape the solar system with the earth and find a new home for mankind. In the entire film, some "hard technology", such as "nuclear fusion technology", "AI recognition technology", "aerospace technology" and so on. All of these provide scientific theoretical support for "Wandering Earth", abandoning illusory and unrealistic imagination, and are the foundation of the existence of science fiction films.

It is true that "Wandering Earth" is slightly rougher than Hollywood science fiction blockbusters. However, the director of the film, Guo Fan, and the entire creative team are still struggling to save and continue to break through in the face of shortage of funds and lack of experience. They spend a lot of money on film scenes, props, special effects, and digital production. For example, they took out more than 3,000 conceptual design drawings, made more than 8,000 sub-lens pictures, produced more than 10,000 props, and completed 2,300 composite shots with special effects, of which $75 \%$ of the special effects were completed by the domestic team. Director Guo Fan said frankly: "We don't have Hollywood special effects technology. Many of the movies are done manually. One shot with the most modification has been modified 251 times. Despite facing al the difficulties, they are still moving forward, creating a very amazing work in the history of Chinese science fiction films.

The success of "Wandering Earth" is a reflection of science and technology and culture after a country has grown into an economic power. China's progress in aerospace, core technology and other fields has also contributed to the birth of "Wandering Earth", which bears cultural soft power, and is the first "Chinese science fiction blockbuster" in the true sense. This is a good start, and it will certainly encourage more people to devote themselves to the Chinese science fiction film industry and promote its development, thus making up for the shortcomings of Chinese science fiction films.

\section{B. Promoting the Core Values of Chinese Tradition}

China is a country with a long history and splendid civilization. Since the 18th National Congress of the 
Communist Party of China, General Secretary Xi Jinping has attached great importance to the development and promotion of Chinese traditional culture, and emphasized: "The core values are the soul of cultural soft power and the focus of cultural soft power construction. The cultural soft power of a country depends fundamentally on the vitality, cohesiveness, and appeal of its core values. Therefore, in a certain sense, in order to enhance China's cultural soft power, it is necessary to use the core values as a guide to play its role as a soul and a core. As a unique cultural carrier, the film can cross the barriers of language and region to better realize the function of cultural communication. In "The Wandering Earth", the core values of Chinese tradition have been vividly presented.

1) Hometown feelings: In the face of the threats to common home earth, Hollywood science fiction films often use "escape" as the main line, abandoning the earth to find new homes, such as "Interstellar" (2014). "Wandering Earth" is quite different. The Chinese have not abandoned the earth, but want to wander around with the earth. In the event of a disaster, the Chinese can even abandon life to protect common home earth.

In the film, the sun is rapidly aging and the earth is in danger of being engulfed. In order to save the planet, humans have built tens of thousands of planetary engines on the surface of the earth to push the earth out of the solar system, and these planetary engines need "flint" to provide energy. On the way to escort "flint" to Hangzhou, Han Zi'ang would rather sacrifice himself than drag the entire rescue team. In the face of the departure of their loved ones, Liu Qi and Duoduo were deeply sad, but for the common home of mankind, they kept up and shouldered the burden of saving the earth. This is the dauntless spirit of protecting the homeland, and it also reflects the deep feelings of the Chinese people.

2) Collectivism: In many science fiction movies, it can see Hollywood's "superheroes" that can save the world. This concept is actually related to the unique way of thinking of Westerners because they advocate "individualism". China has been influenced by Confucianism since ancient times. It believes that heaven, earth and human beings are a harmonious whole. There are also slang words: "people are in harmony, and Taishan can be moved away"; "Great things may be done by mass effort.", etc., all of which reflect "unity is strength." On October 18, 2017, Comrade Xi Jinping pointed out in the report of the 19th National Congress that "it is necessary to strengthen ideological and moral construction and strengthen collectivist education."

In "Wandering Earth", it can also find the core values of the Chinese tradition of "collectivism." First of all, in order to protect the earth, people from all over the world that do not have same skin color and use different languages have united to form a coalition government. Secondly, in order to get the earth out of the solar system, it is necessary to build a planetary engine on a global scale. This is not a country that can be completed and requires people from all over the world to participate. Moreover, when Liu Qi proposed the idea of pushing the earth away from the solar system by the great impact brought by the ignition of Jupiter, they tried hard, initially failed, and at the same time lacked manpower. Later, they tried again. In the last step of pushing the striker to achieve ignition, it can see that rescue teams from all over the world came in and joined, which made people feel moved. In this film, the real hero is not someone, but everyone on the planet. This also shows that perhaps one person's power is negligible, but the collective strength is infinite.

3) Being people-oriented: The "people-oriented" means taking human survival as the foundation. This core value is also demonstrated in "Wandering Earth".

When the space station learned that the earth was about to face disintegration and the rescue was in vain, it decided to abandon the "Wandering Earth Plan" and launch the "Fire Plan", which will store a large number of germ cells and maps of the earth's species in order to continue human civilization on the new planet. Liu Peiqiang is not willing to abandon his loved ones and even give up every life on earth. He decided to sacrifice himself and use the impact of the space station to ignite Jupiter. His behavior is precisely to put the interests of the people in the first place, and is also a vivid interpretation of the "people-oriented" in the core values of Chinese tradition.

\section{Establishing China's National Image}

For a long time, China in the eyes of foreigners was conservative, backward or even feudal. However, these impressions are no longer in line with today's China. In the period of great change in the world, how to better establish China's national image is a key issue. The film has become an important medium for shaping China's national image because of its unique cultural carrier form. A positive national image will lead to a positive understanding and evaluation of a country and its people.

As the first "science fiction blockbuster" in China, "Wandering Earth" has been well received by domestic and foreign audiences. Its emergence is the product of the development of China's film industrialization to a certain stage, and it is also attributed to the significant progress made in China's economic development, aerospace and science and technology, and is an important symbol of a country's comprehensive national strength. This also shows the image of China. In addition, the core Chinese traditional values involved in the film, such as collectivism and peopleoriented, reflect the important concept of China's foreign policy, namely, "living in harmony and achieving joint development". At the same time, in the face of the catastrophe that has befallen the common home of mankind, China has always been guided by the concept of "a community of shared future for mankind", united the strength, sacrificed itself and protected all. These all reflect the national image of China in the new era. This film is also a window for the world to have a new understanding of China. 


\section{CONCLUSION}

Objectively speaking, compared with the world's top science fiction films, "Wandering Earth" has a big gap in terms of special effects production and shooting experience. But the good news is that Chinese science fiction literati and filmmakers have been able to overcome many difficulties and complete China's first truly science fiction blockbuster. This not only brings confidence to Chinese science fiction films, but also greatly enhances the soft power of Chinese film culture.

\section{REFERENCES}

[1] [US] Joseph S. Nye. Soft Power - The mean to Success in World Politics [M]. Beijing: Oriental Publishing House, 2005: 2, 11. (in Chinese)

[2] Xu Dejin. Research on Overseas Communication of Chinese Cultural Soft Power: Current Situation, Problems and Countermeasures [J]. Foreign Language Teaching and Research, 2018, 50(02): 281-291. (in Chinese)

[3] Yang Bowei. A Summary of the Research Status of China's "Cultural Soft Power" [J]. Chinese Culture Research, 2011 (02): 195-203. (in Chinese)

[4] Ouyang Youzhen. Heterogeneity: Collision and Blending of Culture - Internatrional communication of Chinese Film against the background of Globalization [J]. Movie Literature, 2011(09): 16-17. (in Chinese)

[5] Li Yanfeng. Cultivating and Practicing Socialist Core Values in Cultural Confidence $[\mathrm{J}]$. Journal of Guizhou University (Social Science), 2018, 36(06): 119-127. (in Chinese)

[6] Xu Zhiyuan, Zhang Ling. Cultural Soft Power and Socialist Core Values [J]. Studies on Marxism, 2018 (11): 67-73. (in Chinese)

[7] Yuan Wentai. The development of domestic science fiction movies from the perspective of global localization [J]. Movie Literature, 2016 (17): 4-7. (in Chinese)

[8] Yin Hong, Shi Huimin. Chinese Film and National "Soft Image" [J]. Contemporary Film, 2009 (02): 17-20. (in Chinese) 